\title{
Effect of Interferon-Beta on Thyroid Function in Patients of Chronic Hepatitis C without Preexisting Autoimmune Thyroid Disease
}

\author{
YukiHIRO NAGAI, KeNSOU OHSAWA, YASUHIKo IEKI, AND KeN-ICHI KOBAYASHI \\ First Department of Internal Medicine, School of Medicine, Kanazawa University, \\ Kanazawa 920, Japan
}

\begin{abstract}
The effect of interferon-beta (IFN- $\beta$ ) on thyroid function was studied in patients with chronic hepatitis who had no preexisting thyroid disease. Eleven patients ( 9 males and 2 females) aged 20 to 65 years, with a mean age of $47.7 \pm 13.5$ years, were treated with 6 million units of IFN- $\beta$ intravenously every day for 8 weeks. During IFN- $\beta$ administration (4th to 8th week of treatment), both serum free thyroxine $\left(\mathrm{FT}_{4}\right)$ and free triiodothyronine $\left(\mathrm{FT}_{3}\right)$ concentrations decreased significantly $(P<0.0005$ and $P<0.05$, respectively): $\mathrm{FT}_{4}, 1.37 \pm 0.17$ to $1.09 \pm 0.12 \mathrm{ng} / \mathrm{d} l$, and $\mathrm{FT}_{3}, 3.71 \pm 0.45$ to $3.28 \pm 0.34 \mathrm{pg} / \mathrm{ml}$. On the other hand, serum TSH increased significantly from a baseline of $1.70 \pm 0.82$ to $3.34 \pm 1.98 \mu \mathrm{U} / \mathrm{ml}$ during IFN- $\beta$ administration $(P<0.005)$. Four to eight weeks after cessation of treatment, the mean serum $\mathrm{FT}_{4}$ concentration was similar to that during IFN- $\beta$ administration $(1.04 \pm 0.14 \mathrm{ng} / \mathrm{d} l)$, but mean serum $\mathrm{FT}_{3}$ and TSH concentrations returned to pre-treatment levels $\left(\mathrm{FT}_{3}, 3.57 \pm 0.42 \mathrm{pg} / \mathrm{ml}\right.$ and TSH, $1.60 \pm 0.84$ $\mu \mathrm{U} / \mathrm{ml}$ ). Both reverse $\mathrm{T}_{3}$ and thyroglobulin were essentially unchanged. Tests for anti-thyroglobulin and anti-microsomal antibodies were negative in all the patients. These results indicate that IFN- $\beta$ may inhibit thyroid function in patients without preexisting thyroid disease irrespective of humoral immune responses.
\end{abstract}

Key words: Interferon-beta, Thyroid function, Chronic hepatitis

(Endocrine Journal 43: 545-549, 1996)

WITH THE wide use of interferons alpha (IFN- $\alpha$ ) and beta (IFN- $\beta$ ) for the treatment of chronic viral hepatitis and various malignant disorders, it is generally recognized that IFN therapy can induce thyroid dysfunction, either hypothyroidism or hyperthyroidism, by autoimmune mechanisms [1-5]. Although most patients who have developed thyroid dysfunction after IFN therapy have had preexisting autoimmune thyroid diseases, IFN therapy, especially IFN- $\alpha$, also induced thyroid

Received: March 25, 1996

Accepted: May 27, 1996

Correspondence to: Dr. Yukihiro NAGAI, First Department of Internal Medicine, School of Medicine, Kanazawa University, 13-1 Takaramachi, Kanazawa 920, Japan dysfunction in some patients without preexisting thyroid abnormalities [3, 6-8]. In addition to IFNinduced autoimmune phenomena, recent in vitro studies $[9,10]$ demonstrated that both IFN- $\alpha$ and IFN- $\beta$ have direct inhibitory effects on thyrocytes, but there are few reports on direct inhibition of IFN- $\beta$ on thyroid function in clinical studies. In this study, we determined whether IFN- $\beta$ therapy affects thyroid function in patients without preexisting thyroid disease.

\section{Subjects and Methods}

Eleven patients ( 9 males and 2 females) aged 20 to 65 years, with a mean age of $47.7 \pm 13.5$ years, were included in this study. They were all diag- 
nosed as being antibody to hepatitis $C$ virus (anti$\mathrm{HCV}$ ) positive, with chronic hepatitis proven by liver biopsy, and treated with six million units of leukocyte-derived IFN- $\beta$ (Daiichi Pharmaceutical Co., Tokyo, Japan) intravenously every day for eight weeks. All patients had a negative history of thyroid dysfunction prior to this study, and none had goiter on physical examination. All patients gave informed consent for participation in this study. Blood samples were collected three times during the study; before initiation of IFN- $\beta$ treatment, during its administration (4th to 8 th week of treatment) and four to eight weeks after cessation of therapy. In three patients, blood samples were not taken after cessation of therapy. We measured the serum levels of free thyroxine $\left(\mathrm{FT}_{4}\right)$, free triiodothyronine $\left(\mathrm{FT}_{3}\right), \mathrm{TSH}$, reverse triiodothyronine $\left(\mathrm{rT}_{3}\right)$ and thyroglobulin $(\mathrm{Tg})$, and tests for anti-thyroglobulin antibodies (TGHA) and anti-microsomal antibodies (MCHA) were conducted. Liver function (serum albumin, bilirubin, aspartate transaminase, alanine transaminase and cholineesterase levels and prothrombin time) was monitored during this study.

$\mathrm{FT}_{4}, \mathrm{FT}_{3}, \mathrm{rT}_{3}$ and $\mathrm{Tg}$ were measured by radioimmunoassay $\left(\mathrm{FT}_{4}\right.$ and $\mathrm{FT}_{3}$, Amersham Japan, Tokyo, Japan; $\mathrm{rT}_{3}$, Dainabot RI Laboratories, Tokyo, Japan; Tg, Eikenkagaku, Tokyo, Japan), TSH by a two-site immunoenzymometric assay (Tosoh, Yamaguchi, Japan). TGHA and MCHA were measured with the Microtiter Particle Agglutination Test kit (Fujirebio inc., Tokyo, Japan). Normal values were as follows: $\mathrm{FT}_{4}, 0.8-2.3 \mathrm{ng} / \mathrm{dl} ; \mathrm{FT}_{3}, 2.5-6.0$ $\mathrm{pg} / \mathrm{ml} ; \mathrm{TSH}, 0.3-4.5 \mu \mathrm{U} / \mathrm{ml} ; \mathrm{rT}_{3}, 140-410 \mathrm{pg} / \mathrm{ml}$; $\mathrm{Tg},<30 \mathrm{ng} / \mathrm{ml}$; TGHA and MCHA, <1 × $10^{2}$.

Data are given as the mean \pm SD. Statistical analysis was performed by means of paired Student's $t$-test. Significance was defined as a $P$ value less than 0.05 .

\section{Results}

During the first week of IFN- $\beta$ therapy, all patients noted influenza-like symptoms, e.g., high fever, general malaise and anorexia; these symptoms disappeared within 10 days. No patients showed any clinical signs or symptoms of thyroid dysfunction. Both TGHA and MCHA were negative throughout this study in all patients.
Both serum $\mathrm{FT}_{4}$ and $\mathrm{FT}_{3}$ concentrations decreased significantly $(P<0.0005$ and $P<0.05$, respectively) during IFN- $\beta$ administration; $\mathrm{FT}_{4}, 1.37 \pm 0.17$ to $1.09 \pm 0.12 \mathrm{ng} / \mathrm{d} l$, and $\mathrm{FT}_{3}, 3.71 \pm 0.45$ to $3.28 \pm 0.34$ $\mathrm{pg} / \mathrm{ml}$ (Fig. 1). In all patients, both serum $\mathrm{FT}_{4}$ and $\mathrm{FT}_{3}$ concentrations remained above the lower limit of normal during IFN- $\beta$ therapy. After cessation of treatment, the mean serum $\mathrm{FT}_{4}$ concentration was similar to that during IFN- $\beta$ administration $(1.04 \pm 0.14 \mathrm{ng} / \mathrm{d} l)$, and the mean serum $\mathrm{FT}_{3}$ concentration returned to the level before IFN- $\beta$ administration $(3.57 \pm 0.42 \mathrm{pg} / \mathrm{ml})$.

In contrast to the decreases in serum $\mathrm{FT}_{4}$ and $\mathrm{FT}_{3}$ concentrations, mean serum TSH increased sig-
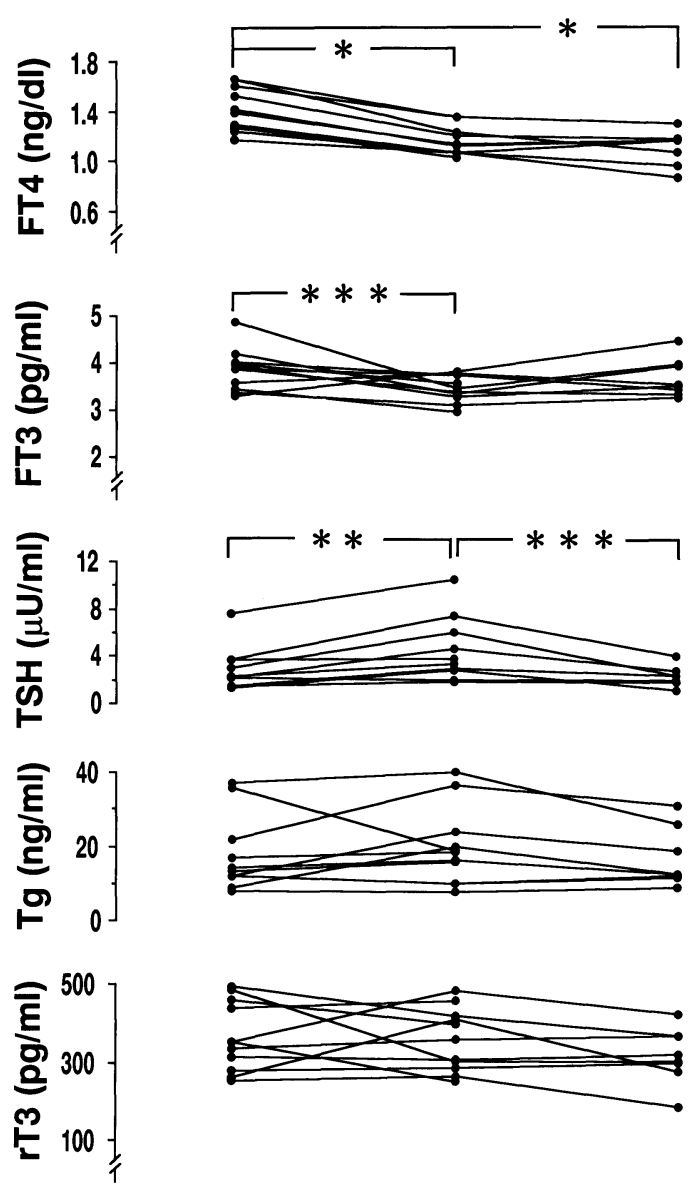

Before Tx During Tx After Tx

Fig. 1. Changes in serum free thyroxine $\left(\mathrm{FT}_{4}\right)$, free triiodothyronine $\left(\mathrm{FT}_{3}\right), \mathrm{TSH}$, thyroglobulin $(\mathrm{Tg})$ and reverse triiodothyronine $\left(\mathrm{rT}_{3}\right)$ before initiation of interferon-beta treatment (Tx), during its administration (4th to 8th week of treatment) and four to eight weeks after cessation of therapy. $*, P<0.0005 ; * *, P<0.005 ; * * *, P<0.05$. 
nificantly from a baseline of $1.70 \pm 0.82$ to $3.34 \pm$ $1.98 \mu \mathrm{U} / \mathrm{m} l$ during IFN $-\beta$ administration $(P<0.005$, Fig. 1). Before the initiation of IFN- $\beta$ therapy, all patients had normal TSH concentrations, but in three patients serum TSH levels were above the upper limit of normal during therapy. After cessation of treatment, mean serum TSH levels returned to pre-treatment levels $(1.60 \pm 0.84 \mu \mathrm{U} /$ $\mathrm{ml}$ ).

As shown in Fig. 1, both mean serum $\mathrm{rT}_{3}$ and $\mathrm{Tg}$ concentrations were essentially unchanged throughout this study.

There was no relation between changes in thyroid function and those in liver function (data not shown).

\section{Discussion}

IFN is useful in the treatment of both certain malignancies and chronic viral hepatitis $[1,11]$, but IFN therapy may lead to autoimmune disease, including thyroid dysfunction [1-5]. The exact mechanism by which IFN- $\alpha$ or $-\beta$ causes thyroid dysfunction is not known. It is controversial as to whether IFN- $\alpha$ or $-\beta$ can induce abnormal expression of major histocompatibility complex (MHC) class II antigens, which play a key role in T-lymphocyte activation as IFN-gamma (IFN- $\gamma$ ) does. But IFN- $\alpha$ has been shown to increase the expression of MHC class I antigens which may cause abnormal presentation of thyroid antigens with consequent activation of cytotoxic $\mathrm{T}$ cells directed against thyrocytes $[12,13]$. In addition, IFN- $\alpha$ or $\beta$ may stimulate a cytokine cascade causing formation of anti-thyroid antibodies, leading to thyrocyte injury [5].

Recently, Taniguchi et al. [5] and Nagayama et al. [8] reported that IFN- $\alpha$ did not induce significant changes in thyroid function in patients with chronic viral hepatitis but no prior history of thyroid dysfunction. There are, however, several contradictory reports indicating that IFN- $\alpha$ therapy induces thyroid dysfunction in patients without preexisting thyroid disease. Among these reports, Del Monte et al. [14] showed a significant reduction in the serum $\mathrm{FT}_{4}$ concentrations after three and six months of IFN- $\alpha$ therapy concomitantly with an increased secretory response of TSH to TRH stimulation. On the other hand, there are few clinical reports about the effect of IFN- $\beta$ therapy on thyroid function in patients without preexisting thyroid disease. Pagliacci et al. [15] reported that IFN- $\beta$ did not affect thyroid function in twenty patients with various hematological malignancies. Our results demonstrate that IFN- $\beta$ therapy reduces serum $\mathrm{FT}_{4}$ and $\mathrm{FT}_{3}$ concentrations and increases the serum TSH concentration, although these changes were within the normal range. The discrepancies between our results and previous studies may be related to: 1 ) a different protocol for IFN- $\beta$ treatment, i.e., administering every day for eight weeks or for seven days alternate weeks for the first six weeks, followed by the same dose twice weekly for the subsequent 24 weeks: 2) a difference in the patient's background, i.e., with chronic viral hepatitis or with hematological malignancies.

Our results showed that all values for thyroid function changed within the normal range except that in three patients serum TSH concentrations were above the upper limit of normal during IFN therapy. It is important to discuss the clinical significance of the change observed. The most interesting evidence we obtained is the increase in the serum TSH concentrations during therapy. Since TSH increases the expression of thyroid autoantigen, microsomal antigen (thyroid peroxidase) $[16,17]$ and thyroglobulin $[18,19]$, the TSH increase induced by IFN may amplify immune responses in autoimmune thyroid disease, and thyroid dysfunction may develop.

In general, a decrease in the serum $\mathrm{rT}_{3}$ concentration is common to all varieties of hypothyroidism [20], but we failed to observe any significant reduction in the serum $\mathrm{rT}_{3}$ concentration, although IFN- $\beta$ might have inhibited thyroid function in this study. The reason for the discrepancy is not clear. One possible explanation is: the serum $\mathrm{rT}_{3}$ concentration will be dependent on not only deficient production of it in hypothyroidism but also a decrease in its metabolic clearance rate in nonthyroid illness [21,22], including chronic liver injury. It is well-known that serum $\mathrm{rT}_{3}$ levels increase secondarily to a decrease in 5'-deiodination of it in patients with nonthyroid illness, often interchangeably termed the low $\mathrm{T}_{3}$ syndrome or sick euthyroid syndrome [21, 22]. It is therefore very difficult to understand the serum $\mathrm{rT}_{3}$ levels in our patients. 
The mechanism by which IFN- $\beta$ inhibits thyroid function is unclear. It is unlikely that changes in thyroid function caused by IFN- $\beta$ are due to activation of humoral immunity, because tests for anti-thyroid antibodies were negative during this study. But, strictly speaking, it is difficult to deny the existence of thyroid autoimmunity by negative tests for TGHA and MCHA, because both TGHA and MCHA are less sensitive in detecting thyroid autoimmunity than RIA kits for anti-thyroglobulin and anti-thyroid peroxidase antibodies. Another possible mechanism is that IFN- $\beta$ acts directly on the thyroid. Murakami et al. [9] reported that IFN$\alpha,-\beta$, and $-\gamma$ can reduce thyroglobulin formation, cAMP levels, and thyroid peroxidase activity in serum-free cultures of thyrocytes from Graves' disease patients. Similarly, Yamazaki et al. [10] recently described the reversible inhibition by IFN$\alpha$ and $-\beta$ of ${ }^{125} I$ incorporation and thyroid hormone release by human thyroid follicles in vitro. They also concluded that IFN therapy would provoke only subtle thyroid dysfunction in a majority of patients without preexisting thyroid autoimmunity since the inhibitory effect was reversible, but in this study, inhibition of thyroid function by IFN- $\beta$ lasted four to eight weeks after cessation of treat- ment. Although the precise mechanism is unclear, IFN- $\beta$ may have toxic as well as functional effects on the thyroid. Another point to consider carefully is the fact that after cessation of IFN- $\beta$ therapy serum TSH levels returned to pre-treatment levels even though serum $\mathrm{FT}_{4}$ levels continued to be low. The precise mechanism of this phenomenon is also unclear. One possible mechanism is that TRH secretion from hypothalamic neurons is decreased by the restoration of serum $\mathrm{FT}_{3}$ levels. The stimulatory effect of TRH on TSH secretion is counterbalanced by the direct pituitary inhibition of TSH by circulating thyroid hormones, named the negative-feedback system. Circulating thyroid hormones also exert an inhibitory effect on TRH secretion from hypothalamic neurons. After cessation of IFN- $\beta$ therapy, serum $\mathrm{FT}_{3}$ levels returned to pre-treatment levels, and subsequently TRH secretion might have been inhibited. But this possibility appears unlikely, as the negative-feedback inhibition exerted by circulating thyroid hormones plays the most important role in the control of TSH secretion from the pituitary gland. A long-term follow-up study may clarify the mechanisms by which these occur.

\section{References}

1. Burman $P$, Totterman $\mathrm{TH}$, Oberg $\mathrm{K}, \mathrm{Karlsson} \mathrm{FA}$ (1986) Thyroid autoimmunity in patients on long term therapy with leukocyte-derived interferon. $J$ Clin Endocrinol Metab 63: 1086-1090.

2. Fentiman IS, Balkwill FR, Thomas BS, Russel MJ, Todd I, Bottazzo GF (1988) An autoimmune aetiology for hypothyroidism following interferon treatment for breast cancer. Eur J Cancer Clin Oncol 24: 1299-1303.

3. Schultz M, Muller R, Von zur Muhlan A, Brabaut $G$ (1989) Induction of hyperthyroidism by interferon-alpha. Lancet 1: 1452.

4. Berris B, Feinman SV (1991) Thyroid dysfunction and liver injury following alpha-interferon treatment of chronic viral hepatitis. Dig Dis Sci 36: 1657-1660.

5. Taniguchi Y, Murakami T, Nakanishi K, Tamai M, Matsuura B, Matsumoto T, Onji M, Tajiri J, Noguchi S, Ohta Y (1992) Two cases of hypothyroidism associated with alpha-interferon therapy. Internal Medicine 31: 373-376.

6. Giles FJ, Worman CP, Jewell AP, Goldstone AH
(1991) Recombinant alpha-interferons, thyroid irradiation and thyroid disease. Acta Haematol 85: 160-163.

7. Lisker-Melman M, Di Bisceglie AM, Usala SJ, Weintraub B, Murray LM, Hoofnagle JH (1992) Development of thyroid disease during therapy of chronic viral hepatitis with interferon alpha. Gastroenterology 102: 2155-2160.

8. Nagayama $Y$, Ohta $K$, Tsuruta M, Takeshita A, Kimura H, Hamasaki K, Ashizawa K, Nakata K, Yokoyama N, Nagataki S (1994) Exacerbation of thyroid autoimmunity by interferon $\alpha$ treatment in patients with chronic viral hepatitis: Our studies and review of the literature. Endocr J 41: 565-572.

9. Murakami T, Tajiri J, Noguchi S, Murakami N, Katou R, Taniguchi Y, Nakanishi K, Ohta Y (1990) Effects of interferon on cultured Graves' thyrocytes. Folia Endocrinol Japon 66: 448 (Abstract)(In Japanese).

10. Yamazaki K, Kanaji Y, Shizume K, Yamakawa Y, Demura H, Kanaji Y, Obara T, Sato K (1993) Reversible inhibition by interferons alpha and beta of ${ }^{125}$ I incorporation and thyroid hormone release by 
human thyroid follicles in vitro. J Clin Endocrinol Metab 77: 1439-1441.

11. Davis GL, Hoofnagle JH (1986) Interferon in viral hepatitis. Role in pathogenesis and treatment. Hepatology 6: 1038-1041.

12. Buller RML, Holmes KL, Hugin A, Frederickson TN, Morse HC (1987) Induction of cytotoxic T cell responses in vitro in the absence of CD4 helper cells. Nature 328: 77-79.

13. Korber B, Mermed N, Hood L, Stroynowski I (1988) Regulation of gene expressions by interferons; Control of H-2 promoter responses. Science 239: 1302-1306.

14. Del Monte P, Bernasconi D, De Conca Valerio, Randazzo M, Meozzi M, Badaracco B, Mesiti S, Marugo M (1995) Endocrine evaluation in patients treated with interferon-alpha for chronic hepatitis C. Horm Res 44: 105-109.

15. Pagliacci MC, Pelicci G, Schippa M, Liberati AM, Nicoletti I (1991) Does interferon- $\beta$ therapy induce thyroid autoimmune phenomena. Horm Metab Res 23: 196-197.

16. Damante G, Chazenbalk G, Russo D, Rapoport B, Foti D, Filetti S (1989) Thyrotropin regulation of thyroid peroxidase messenger ribonucleic acid levels in cultured rat thyroid cells: Evidence for involvement of a non-transcriptional mechanism. Endocrinology 124: 2889-2894.
17. Gerard CM, Lefort A, Libert F, Christophe D, Dumont JE, Vassart G (1988) Transcriptional regulation of the thyroperoxidase gene by thyrotropin and forskolin. Mol Cell Endocrinol 60: 239-242.

18. Lee NT, Nayfeh SN, Choe CB (1989) Induction of nuclear protein factors specific for hormone responsive region during activation of thyroglobulin gene by thyrotropin in rat FRTL-5 cells. J Biol Chem 264: 7523-7530.

19. Nagayama $Y$, Yamashita S, Hirayu H, Izumi M, Uga T, Ishikawa N, Ito K, Nagataki S (1989) Regulation of thyroid peroxidase and thyroglobulin gene expression by thyrotropin in cultured human thyroid cells. J Clin Endocrinol Metab 68: 1155-1159.

20. Chopra IJ (1974) A radioimmunoassay for measurement of 3,3',5'-triiodothyronine (reverse $\mathrm{T}_{3}$ ). J Clin Invest 54: 583-592.

21. Faber J, Thomsen HF, Lumholtz IB, Kirkegaard C, Siersbaek-Nielsen K, Friis T (1981) Kinetic studies of thyroxine, 3,5,3'-triiodothyronine, 3, 3', $5^{\prime}$-triiodothyronine, 3'5'-diiodothyronine, 3,3'-diiodothyronine, and $3^{\prime}$-monoiodothyronine in patients with liver cirrhosis. J Clin Endocrinol Metab 53: 978984.

22. LoPresti JS, Gray D, Nicoloff JT (1991) Influence of fasting and refeeding on 3,3',5'-triiodothyronine metabolism in man. J Clin Endocrinol Metab 72: 130136. 